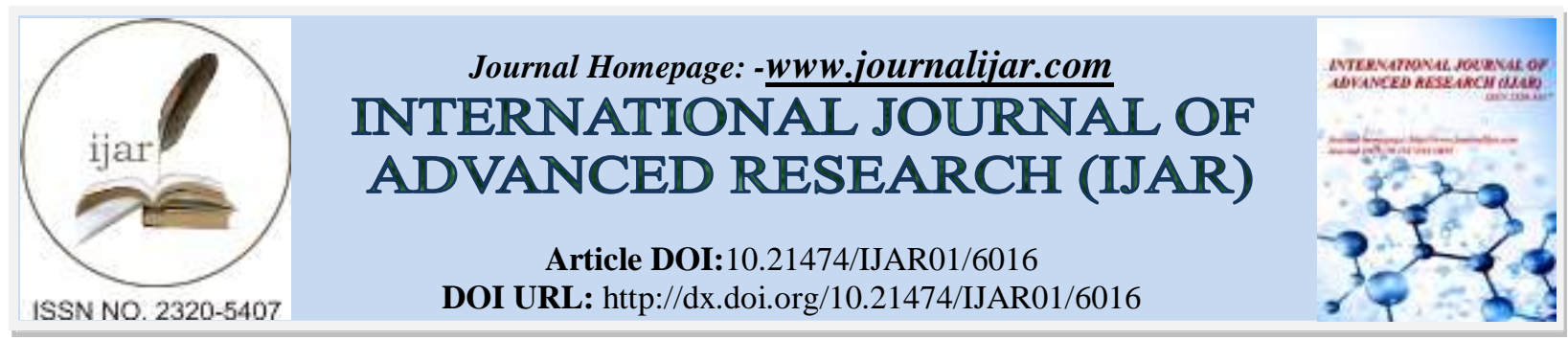

RESEARCH ARTICLE

\title{
SCREENING BIOLOGICAL ACTIVITIES OF ORTHOSIPHON ARISTATUS: SOME OBSERVATIONS.
}

\section{Chithra Vijayan ${ }^{1}$, K Murugan ${ }^{2}$, S R Reji ${ }^{3}$ and G. M. Nair ${ }^{4}$.}

1. Department of Botany, Sree Narayana College, Kollam.

2. Department of Botany, Govt. Arts College, Thiruvananthapuram.

3. Microbiology Division, Jawaharlal Nehru Tropical Botanical Garden \& Reasearch Institute, Palode.

4. Biotechnology Commission, Kerala State Council for Science, Technology and Environment, Thiruvananthapuram.

\section{Manuscript Info}

(n.......................

Manuscript History

Received: 09 October 2017

Final Accepted: 11 November 2017

Published: December 2017

\section{Key words:-}

Orthosiphon aristatus, antioxidant, antimicrobial, anticancer potentiality.

\section{Abstract}

The use of traditional medicine is expanding to newer horizons and plants still remain as the novel source of structurally important compounds that lead to the development of innovative drugs. It is anticipated that plants can provide potential bioactive compounds for the development of new 'leads' to combat various diseases. The systematically performed in vitro assays revealed that the tested plant extract may find in therapy as agent with high pharmaceutical value. In this juncture, the present study was undertaken to analyze the antioxidant, antimicrobial and anticancer potentiality of the medicinal herb Orthosiphon aristatus Benth. The results reveal marginal antibacterial, anti inflammatory and anti cancer activity than the respective standards. Considering anticancer activity, the extract showed high $\mathrm{IC}_{50}$ values for all the cell lines tested. The data on antiinflammatory activity indicate an inhibition percentage of 19.38, when treated with $10 \mu \mathrm{g} / \mathrm{ml}$ of extract while indomethacin produced $54.4 \%$ inhibition. For antibacterial activity, inhibitory values at higher concentrations were quite good. In general, more activity was obtained when using more concentrated decoctions of the plant extract studied. The best results $(60.5 \%$ inhibition) were obtained with antioxidant activity. This study provides evidence that the plant extract have antioxidant properties, as tested through the DPPH method. Therefore, the plant may have great relevance in the prevention and therapies of diseases in which oxidant or free radicals are implicated. The ability of the extracts to scavenge the free radical is an indication of the broad spectrum anti oxidant potential of $O$. aristatus, which make the plant a candidate for bio prospecting for antioxidant drugs. In addition, the plant is a good candidate for further phytochemical and chromatographic studies to isolate and fully characterize the compound related to this in vitro biological activity.

Copy Right, IJAR, 2017,. All rights reserved. 


\section{Introduction:-}

Screening active compounds from plants have lead to the discovery of new medicinal drugs which have efficient protection and treatment roles against various diseases (Sheeja and Kuttan, 2007; Mukherjee et al., 2007; Govindappa et al., 2011). Many of the phytochemical bioactive compounds from medicinal plants have shown many pharmacological activities (Turker and Usta, 2008).

As the focus of medicine shifts from treatment of manifest disease to prevention, increasing awareness on herbal remedies as potential sources of phenolic antioxidants have grown in recent years, and several plants are being screened for their antioxidant properties using different assays. The oxidative stress, defined as "the imbalance between oxidants and antioxidants in favor of the oxidants potentially leading to damage" has been suggested to be the cause of aging and various diseases in humans. In modern western medicine, the balance between antioxidation and oxidation is believed to be a critical concept maintaining a healthy biological system (Finkel, 2000; Tiwari, 2001). Antioxidants play an important role to protect the human body against damage by reactive oxygen species (Gilham et al., 1997).

Plants (fruits, vegetables, medicinal herbs, etc.) may contain a wide variety of free radical scavenging molecules, such as phenolic compounds (e.g. phenolic acids, flavonoids, quinones, coumarins, lignans, stilbenes, tannins), nitrogen compounds (alkaloids, amines, betalains), vitamins, terpenoids (including carotenoids), and some other endogenous metabolites, which are rich in antioxidant activity (Zheng and Wang, 2001; Cai et al., 2003).

There is a great need for standardization of herbal medicine using modern scientific and multidisciplinary approach (Bonati, 1991). This would pave ways for making available medicinal preparations of reliable quality which even a common man can afford. Phytochemical and pharmacological evaluation of Orthosiphon aristatus, which is widely used in the management of various diseases, was carried out in order to assess its efficiency claim and substantiate its pharmacological applications.

\section{Materials and Methods:-}

\section{Plant material:-}

Leaves of Orthosiphon aristatus Benth., used for pharmacological screening, belonging to Lamiaceae, were obtained from collections of medicinal plants maintained in the Garden of Department of Botany, University of Kerala. The collected leaves were washed, chopped into pieces and air dried in the shade, at room temperature $\left(25^{0}\right.$ C) for ten days.

\section{Preparation of plant extract:-}

Air dried leaf samples were powdered separately and used for extraction. $50 \mathrm{~g}$ of the powdered plant portion was filled in a soxhlet extractor and extracted with $300 \mathrm{ml}$ ethanol (boiling point $-64^{0}$ to $65^{\circ}$ ) for ten hours. The extract was transferred to a conical flask, concentrated and evaporated to dryness in a vacuum rotary evaporator under reduced pressure (Harborne, 1998).

\section{Screening for antioxidant activity using DPPH free radical scavenging assay:-}

The free radical scavenging activity of the extract was determined using DPPH stable radical following the methodology described by Molyneux (2004). The absorbance was measured at $517 \mathrm{~nm}$.

\section{Screening for antibacterial activity using disc diffusion method:-}

The ethanolic plant extracts were tested against microorganisms namely Escherichia coli MTCC 443, Pseudomonas aeruginosa MTCC 741, Staphylococcus aureus MTCC 740, and Bacillus subtilis MTCC 10619 in order to determine the antibacterial activity.

Disc diffusion method for detection of antibacterial activity:-

Sensitivity tests were performed by disc diffusion method which is a modified form of Kirby-Bauer test (Cappuccino and Sherman, 1999). Nutrient agar was melted in hot water bath at $90^{\circ} \mathrm{c}$ and allowed to cool. When the temperature reached $50^{\circ} \mathrm{c}$, it was poured to sterile petri dishes under laminar air flow chamber and allowed to solidify in a horizontal position. The culture colonies from the stock cultures were selected and $100 \mu$ was transferred to the culture medium. A sterile spreader was dipped into the properly diluted inoculums and spread evenly. Sterile filter paper disc of diameter $5 \mathrm{~mm}$ (made from Whatman No-1 filter paper) impregnated with extract $(100 \mu \mathrm{g} / \mathrm{ml})$ prepared in $10 \%$ DMSO were placed on the surface of the nutrient agar plates seeded with test 
organisms. They were touched down with a sterile forceps to ensure complete contact with the surface. Then the plates were incubated at $37^{\circ} \mathrm{c}$ for about $24 \mathrm{hrs}$. Control disc impregnated with dimethyl sulphoxide (DMSO) and reference drug (streptomycin - $10 \mu \mathrm{g} / \mathrm{ml}$ ) was also used along with the test disc in each experiment. The plates were examined after $24 \mathrm{hrs}$ incubation. The zone showing incubation was determined by gross virtual examination and the diameter of the zone to the nearest $\mathrm{mm}$ was recorded with a ruler.

\section{MTT assay for determination of anti-cancer activity:-}

The in vitro response of the crude ethanolic fraction of the leaves of $O$. aristatus against five different cell lines, cervical-HeLa, colonHCT116, mouse melanoma-B16F10, breast-MCF7 and Hepatic G2- C3A, was studied using MTT assay. The extent of MTT reduction was measured spectrophotometrically at $570 \mathrm{~nm}$, and the cell survival was expressed as percentage over the untreated control.

\section{Hyaluronidase inhibition assay for determination of anti-inflammatory activity:-}

The assay was performed according to Ling et al. (2003). The assay medium consisted of 3,5 U-hyaluronidase in $100 \mu 20 \mathrm{mM}$ sodium phosphate buffer $\mathrm{pH} 7.0$ with $77 \mathrm{mMNaCl}, 0.01 \%$ BSA preincubated with different concentrations of the test compound ( in DMSO) for $15 \mathrm{~min}$ at $37^{\circ} \mathrm{c}$. After keeping the reaction mixture at room temperature for $10 \mathrm{~min}$, the absorbance was measured at $600 \mathrm{~nm}$. The absorbance in the absence of the enzyme was used as the reference value for maximum inhibition. The inhibitory activity of the test compound was calculated as the percentage ratio of the absorbance in the presence of test compounds vs absorbance in the absence of the enzyme. The enzyme activity was checked by control experiment run simultaneously, in which the enzyme was preincubated with $5 \mu \mathrm{l}$ DMSO instead, and followed by the assay procedures described above. Compounds were tested in a range of $5 \mu \mathrm{g}-250 \mu \mathrm{g}$ in the reaction mixture. Indomethacin was used as reference standard.

Statistical analysis:- Results were analyzed using One way Analysis of Variance (ANOVA) and expressed as mean \pm SE. Data was further subjected to Duncan's post hoc analysis and differences between means were regarded significant at $P<0.05$.

\section{Results:-}

\section{Anticancer activity:-}

In this study, five tumorogenic cell lines including, HeLa, HCT, B16F10, MCF7 and C3A were chosen to determine the anticancer activity of $O$. aristatus extracts. Cultures of HeLa, HCT, B16F10, MCF7 and C3A were treated with increasing concentrations $(5-100 \mu \mathrm{g})$ of the ethanolic extracts of $O$. aristatus (Fig 1a - Fig. 1e). As shown in the figure, for HeLa cells, the cell growth inhibition was $67 \%$ in the presence of plant extract at $50 \mu \mathrm{g} / \mathrm{ml}$ and the activity of this extract reached an IC50 value at $100 \mu \mathrm{g} / \mathrm{ml}$. On HCT, B16F10, MCF7 and C3A the plant extract exhibited no activity. All the cell lines tested showed high $\mathrm{IC}_{50}$ values.

\section{Antibacterial activity:-}

The crude extract of $O$. aristatus was subjected to antibacterial activity against the five pathogenic bacterial strains using disc diffusion method. The antimicrobial activity of the extracts and their potency was quantitatively assessed by the presence / absence of inhibition zone and zone diameter, respectively. The diameter of zone of inhibition was different for each concentration and for each bacterium (Table -1). The extracts showed a good activity against the gram positive bacteria $S$. aureus and $B$. subtilis with a zone diameter of $11 \mathrm{~mm}$, a moderate activity on the gram negative $P$. aeruginosa with an inhibition value of $7 \mathrm{~mm}$ and a weak activity against the gram negative E.coli. Results are given in table 1. At lower concentrations of the extract, no remarkable inhibition zones were noticed. The relative extend of susceptibility of the tested organisms to the plant extract followed a decreasing order of $S$. aureus, B.subtilis, P.aeruginosa and E.coli. In other words $S$. aureus was the most susceptible organism while E.coli was the most resistant microbe studied. The results revealed variability in the inhibitory concentration of extract for each given bacterium.

\section{Antioxidant activity:-}

The change in colour of DPPH from deep violet to yellow is observed in all the concentrations used which is an indication of antioxidant activity. Fig 2 shows the decrease in the concentration of DPPH radical due to the scavenging ability of the ethanolic plant extracts and the commercial standards. In this study we used BHA and BHT as commercial standards. In the present work, the plant extract at $100 \mu \mathrm{g} / \mathrm{ml}$ showed an excellent DPPH radical 
scavenging activity (42.25\%) which was greater than that of the commercial standard used and the activity increased with increasing concentrations (Fig 2). Under same experimental conditions, positive control counter parts, BHA and BHT at $100 \mu \mathrm{g} / \mathrm{ml}$ showed $40.25 \%$ and $55 \%$ DPPH radical scavenging activities, respectively. The $50 \%$ inhibition of DPPH radical by test samples $\left(\mathrm{IC}_{50}\right)$ was observed at a concentration of $125 \mu \mathrm{g} / \mathrm{ml}$ and at the same dosage there was a lower free radical scavenging activity for BHA and a higher activity for BHT, both of which are well known antioxidant compounds.

\section{Antiinflammatory activity:-}

In the present study, the anti inflammatory activity of O.aristatus was assessed by hyaluronidase assay. Indomethacin was used as the positive control which showed significant $(P<0.05)$ anti inflammatory activity in reducing hyaluronidase enzyme. Extract of O.aristatus did not show significant activity in reducing the enzyme, instead showed a trend of anti inflammatory activity $(p<0.05)$ (Fig.3). Treatment with the plant extract showed an $\mathrm{IC}_{50}$ value more than $250 \mu \mathrm{l}$.

\section{Discussion:-}

Plants have become the focus of increasing attention from many research groups in recent years, owing to their exciting chemistry and their wide spectrum of pharmacological activities. Pharmacological screening is performed to allow targeted isolation of new or useful constituents with potential activities. Epidemiological studies over the last three decades have consistently correlated certain diets, specific foods and disease expressions. At the same time, number of bioactive compounds has increased dramatically and a new diet-health paradigm has evolved that emphasizes the positive aspects of diet. The terms "phytochemical", "nutraceutical" and "functional food" have been introduced to describe various aspects of this development (Robards, 2003).

Ethanolic extracts of $O$. aristatus, were evaluated for their potential anticancer, antibacterial, anti-inflammatory and antiradical effects, in the present work.

Successful determination of biologically active compounds from plant materials is largely dependent on the type of solvent used in the extraction procedure. Properties of a good solvent in plant extractions include, low toxicity, easy of evaporation at low heat, promotion of rapid physiologic absorption of the extract, preservative action, inability to cause the extract to complex or dissociate. The factors affecting the choice of solvent are quantity of phytochemicals to be extracted, rate of extraction, diversity of different compounds extracted, diversity of inhibitory compounds extracted, ease of subsequent handling of the extracts, toxicity of the solvent in the bioassay process, potential health hazard of the extractants (Eloff, 1998). The choice of solvent is influenced by what is intended with the extract. Since the end product will contain traces of residual solvent, the solvent should be non-toxic and should not interfere with the bioassay (Tiwari et al., 2011). The choice will also depend on the targeted compounds to be extracted (Ncube et al., 2008; Das et al., 2010).

The traditional healers use water primarily as the solvent, but in the present study we used plant extracts in organic solvent (ethanol). This observation can be rationalized in terms of the polarity of the compounds being extracted by each solvent and in addition to their intrinsic bioactivity, by their ability to dissolve or diffuse in the different media used in the assay. Ethanol is more efficient in cell wall and seed degradations which have non-polar character and cause polyphenols to be released from cells. More useful explanation for the decrease in activity of aqueous extract can be ascribed to the enzyme polyphenol oxidase, which degrade polyphenols in water extracts, whereas in methanol and ethanol they are inactive. Moreover, water is a better medium for the occurrence of the microorganisms as compared to ethanol (Lapornik, 2005). Additionally, ethanol was found easier to penetrate the cellular membrane to extract the intracellular ingredients from the plant material (Wang, 2010). Since nearly all of the identified bioactive components from plants are aromatic or saturated organic compounds, they are most often obtained through initial ethanol or methanol extraction (Cowan, 1999). Methanol is more polar than ethanol but due to its cytotoxic nature, it is unsuitable for extraction in certain kind of studies as it may lead to incorrect results.

The majority of most useful and curative anticancer drugs continue to be derived from plant sources. Doubtlessly, anticancer drugs of biological origin will continue to be of great importance in improving cancer treatment and overall survival rates. Plant extracts that contain several pluripharmacological compounds have been reported to act on multiple molecular and cellular targets and such approach is gaining support to fight cancer. The MTT cell viability assay is widely used in determining drug sensitivity in primary screening of potential chemotherapeutic drug. The MTT Cell Proliferation Assay measures the cell proliferation rate and conversely, when metabolic events 
lead to apoptosis or necrosis, the reduction in cell viability. The extract of O.aristatusshowed moderate activity against the different cell lines tested. The different concentrations of extract did not appreciably alter the rate of apoptosis which act as a prelude to cell destruction.

A compound is judged as a good anticancer drug, when it is more specific towards tumour cells, in comparison to normal cells. Induction of apoptosis in cancer cells or malignant tissues is recognized as an efficient strategy for cancer chemotherapy. A number of antitumour agents including bleomycin, camptothecin, doxorubicin and etoposide have been shown to induce cell death by apoptosis (Waldman et al., 1995; Pereira et al., 2009). In the US NCI plant screening program, a crude extract is generally considered to have in vitro cytotoxic activity if the IC50 value (concentration that causes a 50\% cell kill) in carcinoma cells, following incubation between 48 and 72 hours, is less than $20 \mu \mathrm{g} / \mathrm{ml}$, while it is less than $4 \mu \mathrm{g} / \mathrm{ml}$ for pure compounds (Dahab and Afifi, 2007).

Disk diffusion methods are extensively used to investigate the anti-bacterial activity of natural antimicrobial substances and plant extracts. These assays are based on the use of disks as reservoirs containing the solution of substances to be examined. The antimicrobial activity of the extracts and their potency was quantitatively assessed by the presence / absence of inhibition zone and zone diameter, respectively as shown in table 1 . According to the disc diffusion method for antimicrobial activity, a prominent antibacterial effect, worthy of further investigation was not obtained for all the strains tested. The zones of inhibition by the extracts were compared with the zone of inhibition of reference drug streptomycin. The inhibition zones produced by all the extracts were found to be less than the inhibition zone of streptomycin. Absence of activity was found at lower concentrations when tested against E.coli. The activity was more pronounced against Gram positive than against gram negative bacteria. The reason for the different sensitivity between Gram-positive and Gram-negative bacteria could be ascribed to the morphological differences between these microorganisms, Gram-negative bacteria having an outer phospholipid membrane carrying the structural lipopolysaccharide components. This makes the cell wall impermeable to lipophilic solutes, while porins constitute a selective barrier to the hydrophilic solutes with an exclusion limit of about $600 \mathrm{Da}$ (Nikaido and Vaara,1985).The gram-positive bacteria should be more susceptible having only an outer peptidoglycan layer which is not a selective permeability barrier (Scherrer and Gerhardt, 1971).

Functional foods and beverages are typically developed with specific health goals such as reducing inflammation. Medicinal plants have shown great promise in the management of various inflammatory disorders and have continued to serve as alternative and complementary therapies. One enzyme that is involved in tissue remodeling during inflammation is hyaluronidase, which degrades glycosaminoglycans, including hyaluranan, in human and animal tissues. Hyaluranan polymers are important constituents of the extracellular matrix of connective tissues, including cartilage, the synovial membrane and synovial fluid joints. Many plant derived poyphenolics exert effects on hyaluronidase and other enzymes regulating extracellular matrix metabolism. In this work, the anti hyaluronidase activity of O.aristatuswas tested in vitro in comparison to the widely used indomethacin. The data indicate an inhibition of $19.38,23.45,29.44,33.22$ and $35.62 \%$ of anti-inflammatory activity when treated with 10 , $25,50,100$ and $250 \mu \mathrm{g} / \mathrm{ml}$ of plant extract respectively. The positive control, indomethacin produced $54.4 \%$ inhibition at a concentration of $10 \mu \mathrm{g} / \mathrm{ml}$. Based on the results, it can be concluded that the plant extract cannot be considered as an effective and safer alternative to non - steroidal anti inflammatory drugs.

In the past few years there has been increasing interest in finding natural antioxidants because they can protect the human body from free radicals and ROS related effects and retard the progress of many chronic diseases as well as retard lipid oxidative rancidity in food. Since the DPPH assay can accommodate a large number of sample in a short period and is sensitive enough to detect natural compounds at low concentration, it was used in the present study for a primary screening of the free radical scavenging activity of the crude extract (Anagnostopoulouet al., 2006; Niki, 1987; Ksouriet al., 2007). In the free radical scavenging assay, the effect of the plant extract was equivalent or slightly higher than those of commercial counter parts at the same concentration. All samples showed a dose dependent manner in scavenging DPPH radical that was statistically significant $(\mathrm{p}<0.05)$ when compared with control. The result demonstrates that $O$. aristatusextract has an inhibitory effect on the DPPH radical. In addition, the ability to scavenge the DPPH radical is related to the inhibition of lipid peroxidation (Ratty et al., 1998; Rekka and Kourounakis, 1991; Chang et al., 2001). Thus the plant can be considered as an easily accessible source of natural antioxidant and can be considered as a suitable candidate for antioxidant drug discovery. 


\section{Conclusion:-}

Herbals are indeed all natural sources, represents a virtually untapped reservoir of novel drugs. Taking into account the argument for expanding the exploration of nature as source of novel active agent an attempt to characterize the pharmacological potential of Orthosiphon aristatus Benth. was undertaken. No significant biological potentialities were revealed by the crude extract. Future studies are planned to isolate the lead molecule and its biological characterization.

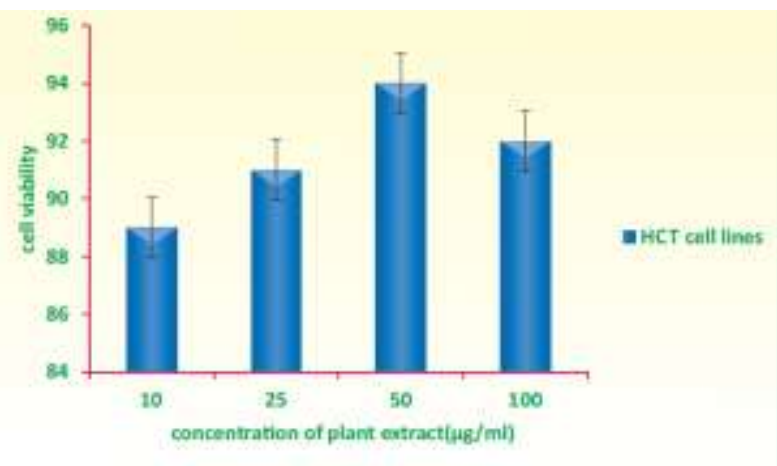

Fig. 1a. Effect of ethanolic extract of $O$. aristatus on HCT cell lines. Data are presented as the mean SE of results from four independent experiments and the error bars indicate standard error. The differences among the mean values were analysed using one way ANOVA followed by Duncan post-hoc analysis

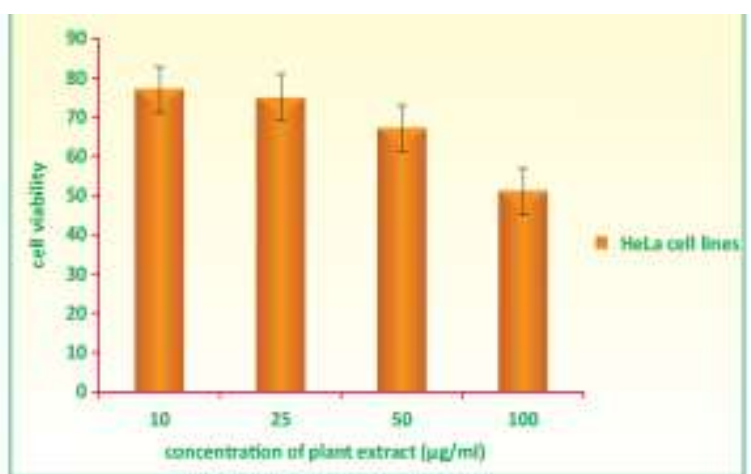

Fig. 1bAnticancer activity of ethanolic extract of $O$. aristatus against $\mathrm{HeLa}$ cell lines. The cell viability was measured in quadruplicate by MTT assay. The results are expressed as the mean percentage of quadruplicate determinations. The differences among the mean values were analysed using one way ANOVA followed by Duncan post-hoc analysis
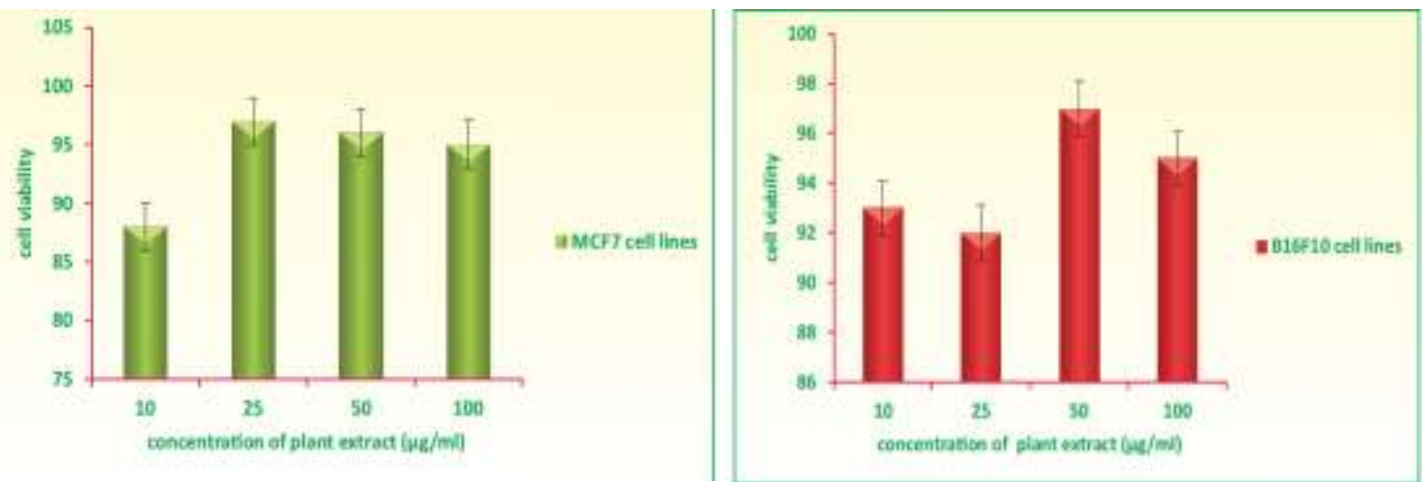

Fig. 1c.Anticancer effect of ethanolic extract of $O$. aristatus against MCF7 cancer cell line. The cell viability was measured by the MTT assay. The results are expressed as the mean percentage of quadruplicate determinations. The differences among the mean values were analysed using one way ANOVA followed bv Duncan post-hoc analvsis
Fig. 1d Shows cell viability on B16F10 cancer cell line at different concentrations by the ethanolic plant extract of $O$. aristatus. Results are the mean $\pm \mathrm{SE}$ of 4 replicates. The differences among the mean values were analysed using one way ANOVA followed by Duncan post-hoc analysis. The error bars indicate standard error 

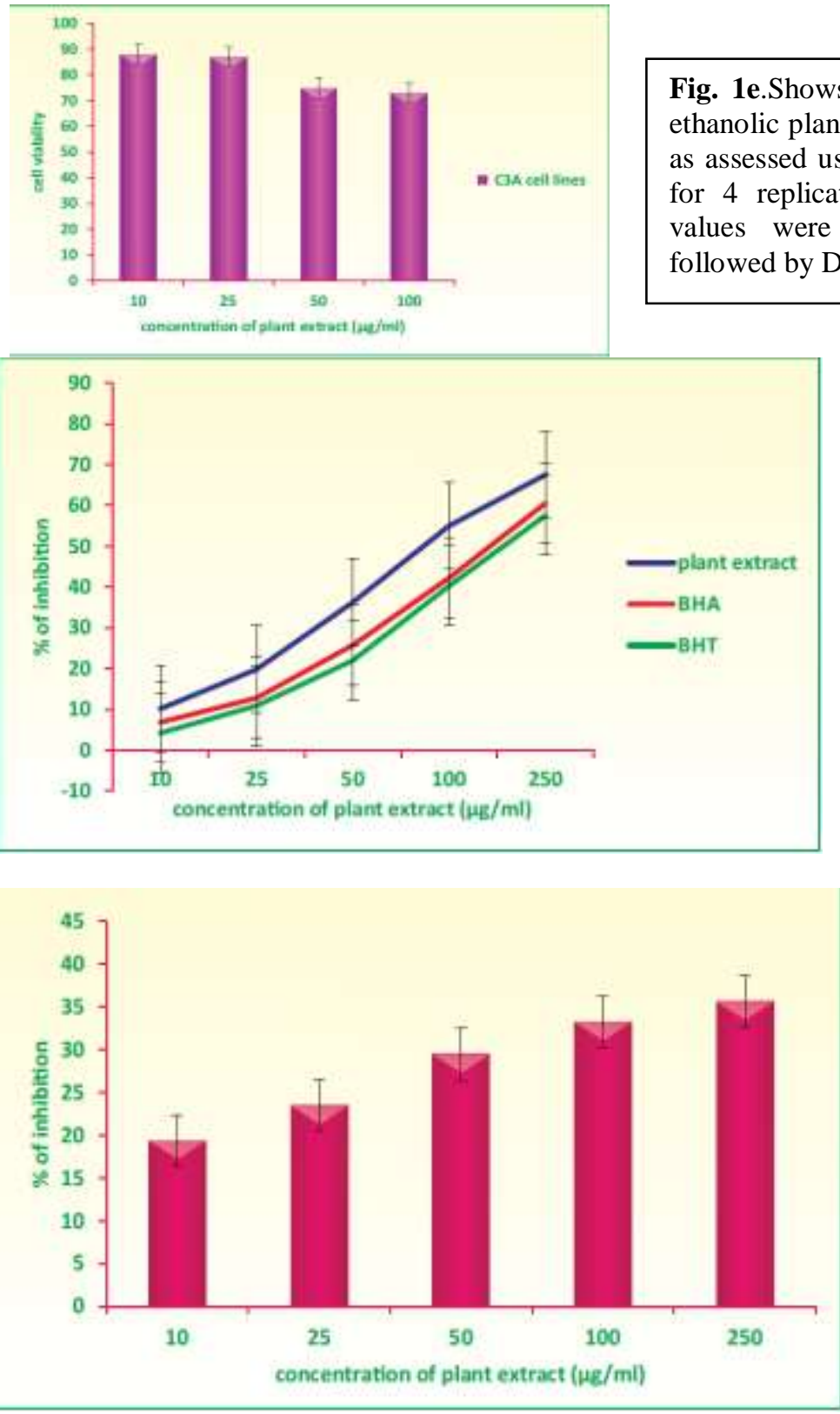

Fig. 2.DPPH radical scavenging activities of ethanolic extract of $O$. aristatus and the reference compounds BHA and BHT. The datarepresent the percentage inhibition of DPPH radical. The results are mean \pm S.D of four parallel measurements

Table I:- Inhibition zone indicating the antibacterial activity of extracts of $O$. aristatus

\begin{tabular}{|c|c|c|c|c|c|c|}
\hline & \multicolumn{5}{|c|}{ Concentration of plant extract used $(\mu \mathrm{g} / \mathrm{ml})$} & \multirow[t]{2}{*}{ Streptomycin } \\
\hline & 10 & 25 & 50 & 100 & 250 & \\
\hline S.aureus & - & + & + & ++ & +++ & +++ \\
\hline B. subtilis & - & - & + & ++ & +++ & +++ \\
\hline E. coli & - & - & - & - & + & +++ \\
\hline P.aeruginosa & - & - & + & + & + & +++ \\
\hline
\end{tabular}




\section{References:-}

1. Govindappa, Sadananda, T.S., Channabasava, R., Jeevitha, M.K., Pooja, K.S. and Raghavendra,V.B. 2011. Antimicrobial, antioxidant activity and phytochemical screening of Tecomastans(L.) Juss. Ex. Kunth. J. Phytol., 3: 68-76

2. Turker, A.U. and Usta, C. 2008. Biological screening of some Turkish medicinal plants for antimicrobial and toxicity studies. Natural Prod., 22: 136-146.

3. Tiwari, A. K. 2001. Imbalance in antioxidant defense and human diseases: Multiple approach of natural antioxidant therapy. Curr. Sc., 8: 1179-1187.

4. Gilham, B., Papachristodoulou, K.D. and Thomas, J.H. 1997. Will's Biochemical Basis of Medicine, Butterworth -Heinemenn, Oxford.

5. Cai, Y.Z., Sun, M. and Corke, H. 2003. Antioxidant activity of betalains from plants of the Amaranthaceae. J. Agric. Food Chem., 51: 2288-2294.

6. Bonati, A. 1991. How and why should we standardize phytopharmacological drugs for clinical validation? J. Ethanopharmacol., 32: 195-197.

7. Harborne, J.B. 1998. Phytochemical Methods - A Guide to Modern Techniques of Plant Analysis. Chapman and Hall, London.

8. Molyneux, P. 2004. The use of the stable free radical diphenylpicrylhydrazyl (DPPH) to estimate antioxidant activity.Songklanakarin J. Sci. Technol., 26: 211-219.

9. Cappuccino, J.G. and Sherman, N.1999. Microbiology: A laboratory Manual. Addison Wesley Longman, Inc. Harlow, England, 254-256.

10. Ling, S.K. Tanaka, T. and Kouno, I. 2003.Effects of iridoids on lipoxygenase and hyaluronidase activities and their activation by $\beta$-glucosidase in the presence of amino acids. Biol. Pharm. Bull., 26: $352-356$.

11. Robards, K. 2003. Strategies for the determination of bioactive phenols in plants, fruit and vegetables. J.Chroma. A, 1000: 657-691.

12. Eloff, J.N. 1998. Which extractant should be used for the screening and isolation of antimicrobial components from plants. J. Ethnopharmacol., 60: 1-8

13. Tiwari, P., Kumar, B., Kaur,M., Kaur, G. and Kaur, H.2011. Phytochemicalscreening and Extraction: A Review. International Pharmaceut. Sci.,1: 98-106.

14. Das, K., Tiwari, R.K.S. and Shrivastava, D.K. 2010. Techniques for evaluation of medicinal plant products as antimicrobial agent: Current methods and future trends. J. Med. Plants Res.,4: 104-111.

15. Lapornik, B., Prosek, M. and Wondra, A. G. 2005. Comparison of extracts prepared from plant by-products using different solvents and extraction time. J. Food Eng., 71: 214-222.

16. Wang, G.X. 2010.In vivo anthelmintic activity of five alkaloids from Macleayamicrocarpa (Maxim) Fedde against Dactylogyrusintermedius in Carassiusauratus.Vet.Parasitol., 171: 305-313

17. Cowan, M.M. 1999. Plant products as antimicrobial agents. Clin.Mic. Biol.Rev., 12: 564-582.

18. Pereira da Silva, A.P.P., El-Bacha, T., Kyaw, N., dos Santos, R.S., da-Silva, W.S., Almeida, F.C., da Poian, A.T. and Galina, A. 2009. Inhibition of energy- producing pathways of HepG2 cells by 3-bromopyruvate. Biochem. J., 417: 717-726

19. Dahab, R. A. and Afifi, F. 2007. Antiproliferative activity of selected medicinal plants of Jordan against a breast adenocarcinoma cell line (MCF7). Sci. Pharm., 75: 121-136

20. Nikaido, H. and Vaara, M. 1985. Molecular basis of bacterial outer membrane permeability. Microbiol.Rev., 1: 1-32.

21. Scherrer, R. and Gerhardt, P. 1971. Molecular sieving by the Bacillummegaterium cell wall and protoplast.J .Bacteriol.,107: 718-735

22. Ksouri, R., Megdiche, W., Debez, A., Falleh, H., Grignon, C. and Abdelly, C. 2007. Salinity effects on polyphenol content and antioxidant activities in leaves of the halophyte Cakilemaritima. Plant Physio. Biochem., 45: 244 - 249.

23. Chang, S.T., Wu, J.H., Wang,S.Y., Kang, P.L., Yang,N.S. and Shyur, L.F. 2001. Antioxidant activity of extracts from Acacia confusa bark and heartwood. J. Agric. Food Chem., 49:3420-3424. 